\title{
Relação entre imagem e texto na tradução do livro infantil Commotion in the ocean
}

\author{
Jucimara Sobreira de Campos
}

Resumo: Este artigo traz o relato da experiência de tradução de um livro infantil, que envolve um processo de análise das escolhas feitas pelo tradutor, tendo como base as imagens e sua relação semântica com o texto. Ambos completam-se e, ao mesmo tempo, trazem uma forma independente de diálogo com o público infantil, visto que o leitor mais jovem, que ainda não lê, sente-se seduzido pela forma, colorido e aspecto descritivo apresentados pelos desenhos. As crianças mais velhas aliam esses recursos ao prazer do texto, elaborado com a finalidade não somente de atrair sua atenção, mas também estimular sua curiosidade. O trabalho do tradutor de livros infantis é o de transportar essas sensações para os leitores da língua de chegada, considerando, sobretudo que, embora trabalhando exclusivamente com o texto, são as imagens que permearão o resultado. Mostrar alguns dos recursos usados numa tradução desse tipo é o objetivo do presente relato.

Palavras-chave: tradução; literatura infantil; imagem e texto.

\section{Introdução}

Commotion in the Ocean é um livro infantil de Giles Andreae com ilustrações de Davis Wojtowycz, dupla que também produziu Rumble in the Jungle. Giles Andreae é o criador da personagem Purple Ronnie, responsável por tornar o autor um ícone da cultura popular na Inglaterra. Recebeu os prêmios Red House Best Picture Book Award in 1998 por The Lion Who Wanted to Love e, em 2003, por Pants. Seu livro Giraffes Can't Dance é conhecido como um clássico internacional da literatura infantil. Davis Wojtowycz, mais conhecido por seu sucesso no mercado de cartões, com mais de 350 publicados com sua marca Pigs Might Fly, repetiu o sucesso ao ilustrar Rumble in the Jungle e The Lion Who Wanted to Love. 
Do início ao fim dessa viagem ao fundo do mar, através de versos rimados que contam a vida das muitas e diversas espécies de vida marinha, o livro é um conjunto de arte, ritmo e rimas (estas presentes já no título) e elementos visuais predominantemente em azul, com cores vivas, que atraem o olhar infantil e são a estrela desse trabalho, pois constituem por si só um enredo visual de mensagens imediatas magistralmente elaborado.

\section{Relação imagem-texto}

Para realizar esse tipo de tradução, o primeiro aspecto a ser levado em conta são as ilustrações. Se no processo de produção editorial as ilustrações, na maioria das vezes, acontecem posteriormente ao texto, como forma de complemento a ele, durante o ato tradutório elas servem como o fio condutor do trabalho do tradutor, restringindo as opções de adequação, adaptação ou substituição. Em sua análise sobre a relação texto-imagem, Azenha (1995, p. 154) observa:

Também na tradução de literatura, sobretudo de literatura infantojuvenil, o uso da imagem ora opera no sentido de facilitar o trabaIho do tradutor (por exemplo, na economia de texto verbal para a descrição de personagens e cenários do imaginário infantil), ora the estabelece limites (por exemplo, quando a ilustração traz dizeres, siglas, abreviaturas, ou então quando retrata um cenário exótico para a cultura de partida, mas que nada tem de exótico para a cultura de chegada).

Embora não haja características culturais distintas no livro em questão, já que o universo marinho traz elementos universalmente presentes no imaginário infantil, as ilustrações são tão significativas que não foi possivel transbordar criatividade e isso gerou uma dificuldade para a tradução. $O$ texto teve que submeter-se à ilustração.

Com relação ao texto, dentro do aspecto fonológico encontramos as rimas que exigiram um trabalho de pesquisa sinonímica e que serviu de suporte à sua "re"-criação dentro dos recursos do idioma. Um dos objetivos foi criar a sonoridade da leitura, como afirma Jekino (SBS ETALK):

[...] ler em voz alta, etapa fundamental para quem quer fazer uma boa tradução para crianças. Lembre-se de que é comum o livro ser lido pela mãe, pelo pai, tia, professor etc., ou mesmo pela própria criança em voz alta. 
Comentaremos algumas estratégias de escolha de determinados pares de rimas e onomatopéias usadas, assim como faremos algumas considerações pertinentes ao processo de tradução desse livro originalmente escrito no idioma inglês.

1. A omissão da cor "branca" do urso polar deveu-se à preservação da métrica, uma vez que algum acréscimo teria que ser feito, como o acréscimo de " $e$ " na construção "grande e branco urso polar"; ou uma vírgula para a opção "grande, branco, urso polar", gerando uma pausa que comprometeria métrica e ritmo. Dessa forma, minha opção foi por "o grande urso polar".

2. A escolha das onomatopéias "clic-clic" "fiu-fiu" para encontrar a rima com assobio, levou em consideração o recurso usado pelo autor, de valerse de palavras que têm a carga semântica de um som específico: click (estalar), whistle (assovio ou apito) e squeak (grunhir).

3. O nome composto Acará Bandeira, para substituir o também composto Angel fish só foi usado no título, pois, se usado no primeiro verso, comprometeria tanto a métrica quanto o ritmo. Entretanto, a opção de deixar "Bandeira" no título torna-se quase imperativa, visto que o peixinho em questão é todo listrado em verde e amarelo.

4. Usei o verbo "nadar" em: "A arraia nada segura". Somente na leitura em voz alta percebeu-se a idéia dupla de "nada". Para preservar o duplo sentido de "nada", tirei o "mas" no início do terceiro verso. Outra opção para substituir "nada" seria "flutua".

5. A fim de preservar o uso das onomatopéias que deram ao texto a sensação de rapidez, criei sons como "zummm" e "tlic, tlic" e acrescentei palavras mais descritivas, que, embora tenham aumentado o texto, não comprometeram a métrica na leitura em voz alta.

6. A palavra "milhas" não faz parte das medidas do sistema brasileiro, mas tem uma sonoridade familiar, muitas vezes mantidas assim tanto em desenhos animados (presença muito forte no universo infantil), como em vários livros.

7. "Barnacles" tem como definição "cirrípedes (crustáceos hermafroditas que vivem fixos em rochas)". "Marisco", apesar de não corresponder à tradução exata do termo, cumpre bem a função, pois são da mesma cor e característica da ilustração, além de serem encontrados grudados nas pedras. 


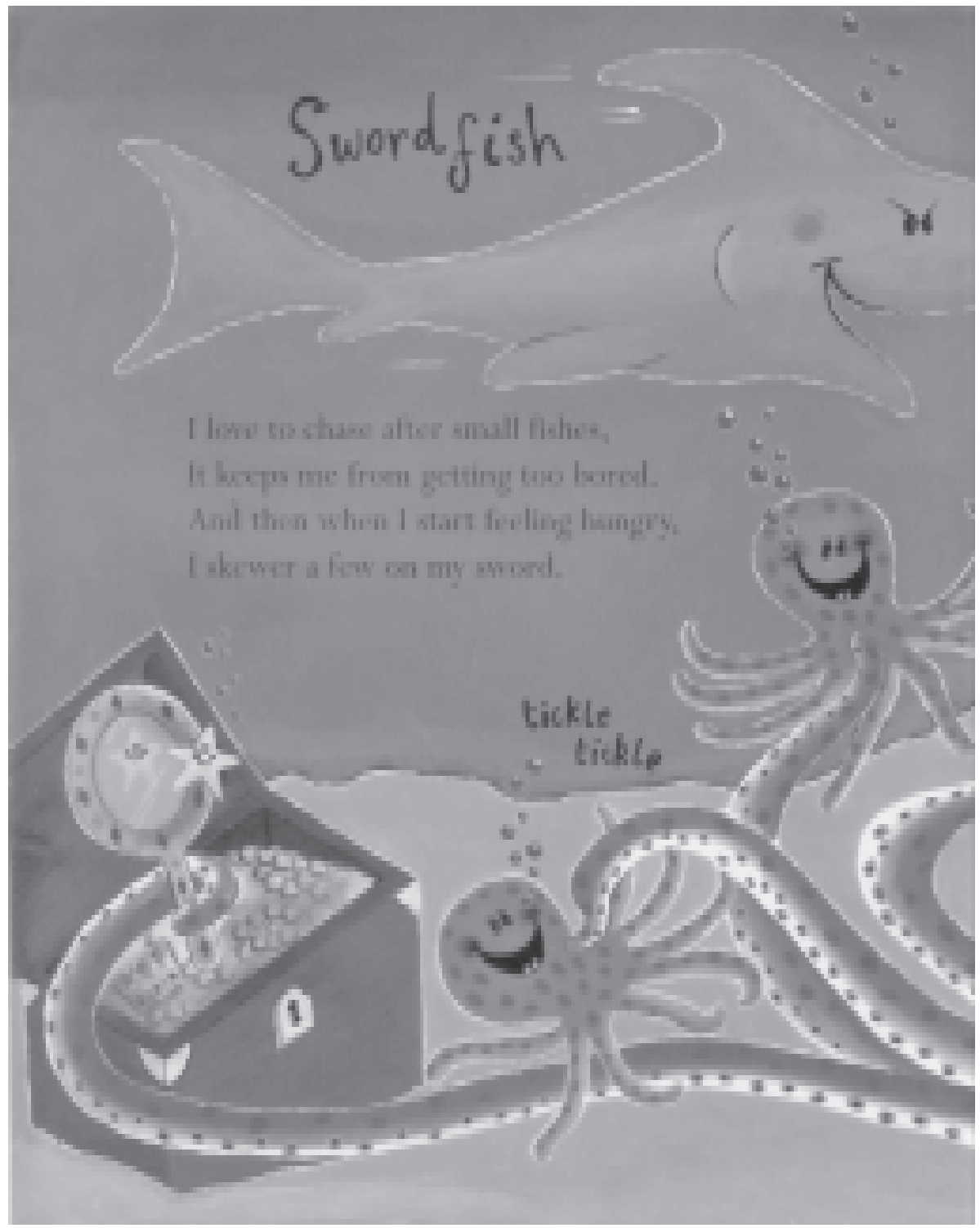




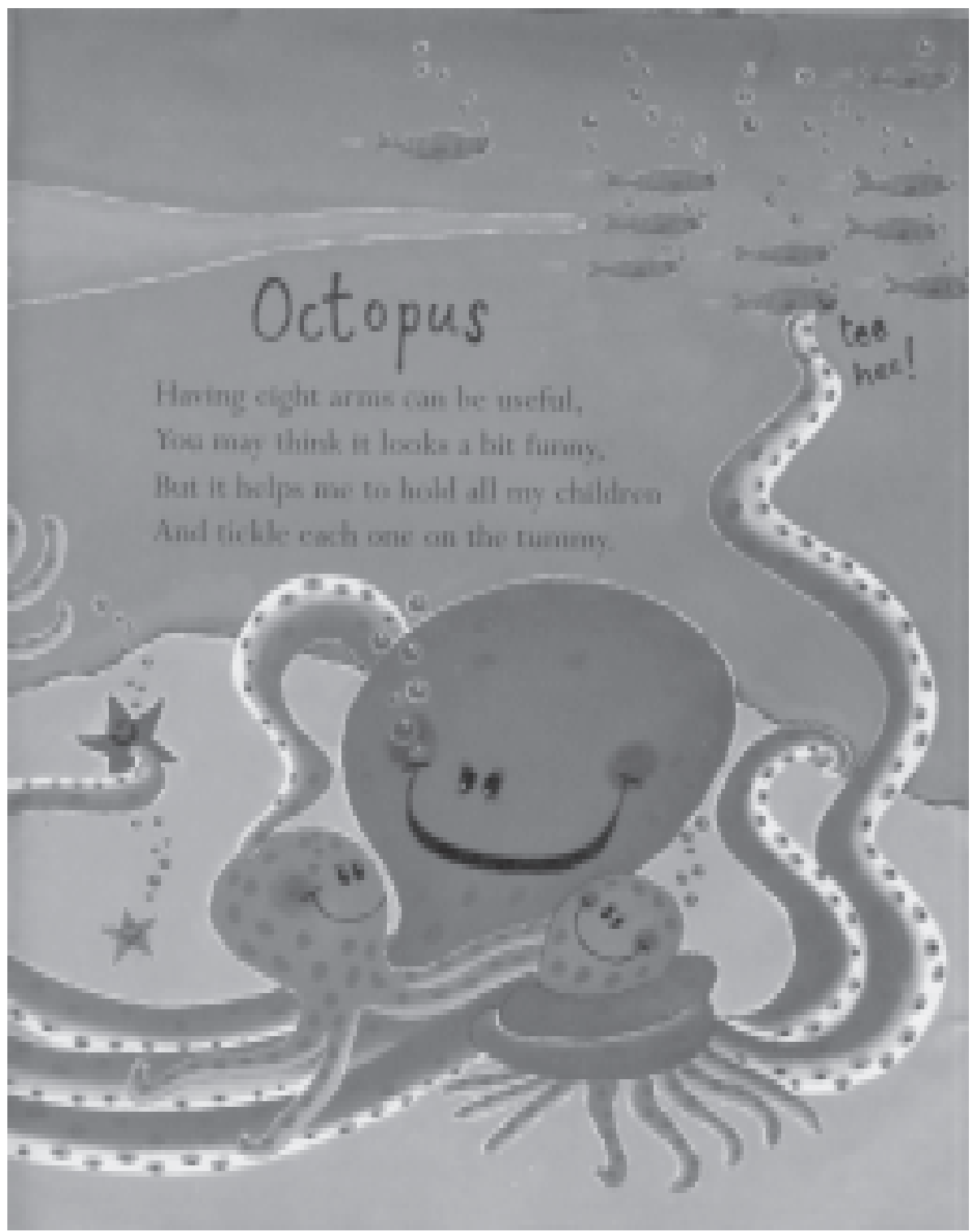

[Figuras 1 e 2. O polvo com seus tentáculos tocando cada filhote. Giles Andeae e David Wojtowycz. Commotion in the Ocean, London, Scholastic, 1998.] 


\section{Considerações finais}

O trabalho de tradução do livro infantil aqui apresentado teve como característica principal a sonoridade e musicalidade das rimas e foi definido e guiado pelas ilustrações, responsáveis diretas pela mensagem. Qualquer criança sente prazer ao olhar para um livro como esse. Se ela ainda não sabe ler, o simples fato de admirar a arte - nesse caso belíssima - Ihe dará informações sobre o fundo do mar. Pelo menos dois sentidos, então, são aguçados com este livro: o da visão, obviamente pelas belas ilustrações, e o da audição: ao ouvirem outra pessoa lendo os versinhos, os pequenos se sentirão atraídos pela musicalidade das rimas.

\begin{tabular}{|l|l|}
\hline $\begin{array}{l}\text { Commotion in the ocean } \\
\text { There's a curious commotion } \\
\text { At the bottom of the ocean. } \\
\text { I think we ought to go and take a look... }\end{array}$ & $\begin{array}{l}\text { Plano no oceano } \\
\text { Existe um curioso plano } \\
\text { No fundo do oceano } \\
\text { Acho que podemos olhar agora. }\end{array}$ \\
\hline $\begin{array}{l}\text { You'll find every sort of creature } \\
\text { That lives beneath the sea } \\
\text { Swimming through the pages of this book. }\end{array}$ & $\begin{array}{l}\text { Tem todo tipo de criatura } \\
\text { Que vive embaixo do mar }\end{array}$ \\
\hline $\begin{array}{l}\text { There are dolphins, whales, and penguins, esse livro afora. } \\
\text { There are jellyfish and sharks } \\
\text { There's the turtle and the big white } \\
\text { polar bear. }\end{array}$ & $\begin{array}{l}\text { Tem golfinhos, baleias e pinguins, } \\
\text { Tem água viva e tubarão, } \\
\text { Tem tartaruga e o grande urso polar. } \\
\text { (1) }\end{array}$ \\
\hline $\begin{array}{l}\text { But can you see behind the wrecks } \\
\text { And in between the rocks? } \\
\text { Let's take a look and find who's hiding there... }\end{array}$ & $\begin{array}{l}\text { Mas você consegue ver atrás dos destroços } \\
\text { Vamos ver quem podemos encontrar... }\end{array}$ \\
\hline $\begin{array}{l}\text { Crab } \\
\text { The crab likes walking sideways } \\
\text { And I think the reason why } \\
\text { Is to make himself look sneaky } \\
\text { And pretend that he's a spy. }\end{array}$ & $\begin{array}{l}\text { Caranguejo } \\
\text { O caranguejo gosta de andar de lado } \\
\text { E eu acho que sei a razão. } \\
\text { É pra se fazer de quietinho } \\
\text { E fingir que é um espião. }\end{array}$ \\
\hline
\end{tabular}




\begin{tabular}{|c|c|}
\hline $\begin{array}{l}\text { Turtles } \\
\text { We crawl up the beach from the water } \\
\text { To bury our eggs on dry land. } \\
\text { We lay a whole batch, } \\
\text { And then when they hatch, } \\
\text { They scamper about in the sand }\end{array}$ & $\begin{array}{l}\text { Tartarugas } \\
\text { Nós nos arrastamos do mar para a areia } \\
\text { Para enterrar nossos ovos contentes. } \\
\text { Não botamos um, botamos bastantes, } \\
\text { E quando os filhotes nascem cambaleantes, } \\
\text { Rastejam para o mar impacientes. }\end{array}$ \\
\hline $\begin{array}{l}\text { Dolphins } \\
\text { The wonderful thing about dolphins } \\
\text { Is hearing them speak. } \\
\text { It's not: "how do you do?" } \\
\text { As I'd say to you } \\
\text { It's more of a "click- whistle- squeak!" }\end{array}$ & $\begin{array}{l}\text { Golfinhos } \\
\text { A beleza dos golfinhos } \\
\text { É que falam com um assobio } \\
\text { Não é "como vai amigo?" } \\
\text { Como você faz comigo } \\
\text { É mais "clic-clic, fiu-fiu" }\end{array}$ \\
\hline $\begin{array}{l}\text { Angel fish } \\
\text { Hello, I'm the angelfish, darling, } \\
\text { The prettiest thing in the sea. } \\
\text { What a shame there are no other creatures } \\
\text { As gorgeous and lovely as me! }\end{array}$ & $\begin{array}{l}\text { Acará bandeira (3) } \\
\text { Oi, eu sou o acará, queridos, } \\
\text { A coisa mais linda do mar, } \\
\text { Que pena que não há outras criaturas } \\
\text { Tão maravilhosas para admirar! }\end{array}$ \\
\hline $\begin{array}{l}\text { Jellyfish } \\
\text { The jellyfish just loves to jiggle } \\
\text { Which other fish think is quite dumb. } \\
\text { She knows that it's not all that useful } \\
\text { But jiggling's lots of good fun. }\end{array}$ & $\begin{array}{l}\text { Água viva } \\
\text { A água viva adora bailar } \\
\text { E os outros peixes não veem sentido. } \\
\text { Ela sabe que isso não serve pra nada } \\
\text { Mas dançar é muito divertido. }\end{array}$ \\
\hline $\begin{array}{l}\text { Shark } \\
\text { I swim with a grin up to greet you, } \\
\text { See how my jaws open wide. } \\
\text { Why don't you come a bit closer? } \\
\text { Please, take a good look inside... }\end{array}$ & $\begin{array}{l}\text { Tubarão } \\
\text { Eu nado com um sorriso pra você, } \\
\text { Veja, minha boca é a maior do mundo. } \\
\text { Por que não chega mais perto? } \\
\text { Vamos, olhe bem lá no fundo... }\end{array}$ \\
\hline $\begin{array}{l}\text { Swordfish } \\
\text { I love to chase after small fishes, } \\
\text { It keeps me from getting too bored. } \\
\text { And then when I start feeling hungry, } \\
\text { I skewer a few on my sword. }\end{array}$ & $\begin{array}{l}\text { Peixe-espada } \\
\text { Adoro perseguir os peixes pequenos, } \\
\text { É assim que mantenho a vida ocupada. } \\
\text { E aí quando eu começo a sentir fome, } \\
\text { Espeto alguns com minha espada. }\end{array}$ \\
\hline
\end{tabular}




\begin{tabular}{|c|c|}
\hline $\begin{array}{l}\text { Octopus } \\
\text { Having eight arms can be useful, } \\
\text { You may think it looks a bit funny. } \\
\text { But it helps me to hold all my children } \\
\text { And tickle each one on the tummy }\end{array}$ & $\begin{array}{l}\text { Polvo } \\
\text { É muito bom ter oito braços, } \\
\text { Você pode achar engraçado } \\
\text { Mas me ajuda a abraçar meus filhotes } \\
\text { E em todos fazer um agrado. }\end{array}$ \\
\hline $\begin{array}{l}\text { Stingray } \\
\text { At the bottom of the ocean } \\
\text { The stingray flaps his wings. } \\
\text { But don't you get too close to him, } \\
\text { His tail really stings! }\end{array}$ & $\begin{array}{l}\text { Arraia } \\
\text { No fundo do oceano } \\
\text { A arraia nada segura.(4) } \\
\text { Não chegue tão perto dela, } \\
\text { Sua cauda realmente fura! }\end{array}$ \\
\hline $\begin{array}{l}\text { Lobster } \\
\text { Never shake hands with a lobster. } \\
\text { It isn't a wise thing to do, } \\
\text { With a clippety-clap } \\
\text { And a snippety-snap. } \\
\text { He would snip all your fingers in two }\end{array}$ & $\begin{array}{l}\text { Lagosta } \\
\text { Nunca aperte a mão de uma lagosta. } \\
\text { Suas patas parecem alicates. } \\
\text { Zummm como um torpedo, } \\
\text { E,tlic-tlic, como um brinquedo, (5) } \\
\text { Corta seus dedos em duas partes. }\end{array}$ \\
\hline $\begin{array}{l}\text { Deep sea } \\
\text { Milles bellow the surface } \\
\text { Where the water's dark and deep, } \\
\text { Live the most amazing creatures } \\
\text { That you could ever meet. }\end{array}$ & $\begin{array}{l}\text { Fundo do mar } \\
\text { Milhas abaixo da superfície (6) } \\
\text { Onde o mar é escuro e profundo } \\
\text { Vivem as mais curiosas criaturas } \\
\text { Que se pode encontrar no mundo. }\end{array}$ \\
\hline $\begin{array}{l}\text { There are fish of all descriptions } \\
\text { Of every shape and size } \\
\text { Some have giant pointy teeth } \\
\text { And great big bulging eyes. }\end{array}$ & $\begin{array}{l}\text { Tem peixes de todos os tipos, } \\
\text { De todos os jeitos e tamanhos. } \\
\text { Alguns têm dentes grandes e pontudos, } \\
\text { E olhos enormes e estranhos. }\end{array}$ \\
\hline $\begin{array}{l}\text { Some of them can walk around } \\
\text { And balance on their fins. } \\
\text { But the strangest fish of all } \\
\text { Have glowing whiskers on their chins! }\end{array}$ & $\begin{array}{l}\text { Alguns vão e vêm } \\
\text { Usando as nadadeiras. } \\
\text { Mas a mais estranha de todas } \\
\text { Tem bigodes brilhantes na boca inteira! }\end{array}$ \\
\hline
\end{tabular}




\begin{tabular}{|c|c|}
\hline $\begin{array}{l}\text { Blue whale } \\
\text { There's no other beast on the planet } \\
\text { As big as the giant blue whale } \\
\text { He measures a massive one hundred feet long } \\
\text { From his head to the tip of his tail }\end{array}$ & $\begin{array}{l}\text { Baleia azul } \\
\text { Não há outro bicho no planeta } \\
\text { Maior do que a baleia azul gigante. } \\
\text { São } 30 \text { metros de comprimento } \\
\text { Em um corpo nada elegante. }\end{array}$ \\
\hline $\begin{array}{l}\text { Barnacles } \\
\text { We're just a bunch of barnacles } \\
\text { And all we do is cling } \\
\text { We know it's not that glamorous } \\
\text { But it's our favorite thing! }\end{array}$ & $\begin{array}{l}\text { Mariscos ( } 7 \text { ) } \\
\text { Somos só um monte de mariscos } \\
\text { E só sabemos grudar. } \\
\text { Não, não é nada charmoso } \\
\text { Mas é muito, muito gostoso! }\end{array}$ \\
\hline $\begin{array}{l}\text { Walruses } \\
\text { Our bodies are covered with blubber } \\
\text { And our tusks are incredibly long. } \\
\text { We're grumpy and proud } \\
\text { And we bellow out loud } \\
\text { To show that we're mighty and strong }\end{array}$ & $\begin{array}{l}\text { Morsa } \\
\text { Nossos corpos são cobertos de gordura } \\
\text { E nossas presas muito compridas. } \\
\text { Somos bravas e orgulhosas, } \\
\text { E com nossas vozes poderosas, } \\
\text { Somos fortes e destemidas. }\end{array}$ \\
\hline $\begin{array}{l}\text { Penguins } \\
\text { We waddle around on our icebergs } \\
\text { Which makes our feet slither and slide } \\
\text { And when we get close to the water } \\
\text { We leap with a splash off the side. }\end{array}$ & $\begin{array}{l}\text { Pinguins } \\
\text { Caminhamos na neve deslizando, } \\
\text { O que deixa nosso andar gingado. } \\
\text { E quando pulamos na água, } \\
\text { Espirramos água pra todo lado, }\end{array}$ \\
\hline $\begin{array}{l}\text { Polar bears } \\
\text { Deep out in the Arctic } \\
\text { The mommy polar bear } \\
\text { Snuggles up with all her children } \\
\text { Since it's very cold out there. }\end{array}$ & $\begin{array}{l}\text { Urso polar } \\
\text { Bem no meio do Ártico, } \\
\text { A mamãe urso polar } \\
\text { Abraça todos os filhotes } \\
\text { Porque é frio de arrepiar. }\end{array}$ \\
\hline $\begin{array}{l}\text { What a lot of creatures } \\
\text { We have seen beneath the sea } \\
\text { What a lot of funny things they do. }\end{array}$ & $\begin{array}{l}\text { Que monte de criaturas } \\
\text { Vimos embaixo do mar, } \\
\text { Fazendo muita graça e auê. }\end{array}$ \\
\hline $\begin{array}{l}\text { Some of them might lick their lips } \\
\text { And eat you in one bite } \\
\text { And some might want to swim around with you. }\end{array}$ & $\begin{array}{l}\text { Algumas podem lamber os lábios } \\
\text { E te comer com uma mordida, } \\
\text { Outras só querem nadar com você. }\end{array}$ \\
\hline
\end{tabular}




\begin{tabular}{|l|l|}
\hline $\begin{array}{l}\text { The dolphin's very friendly } \\
\text { And the lobster's very fierce, } \\
\text { But the shark is the most dangerous by far }\end{array}$ & $\begin{array}{l}\text { O golfinho é muito gentil } \\
\text { E a lagosta muito poderosa, } \\
\text { Mas o mais perigoso é o tubarão. }\end{array}$ \\
\hline $\begin{array}{l}\text { Can you name the other friends } \\
\text { We've made along the way? } \\
\text { See if you can tell me who they are. }\end{array}$ & $\begin{array}{l}\text { Você se lembra dos outros amigos } \\
\text { Que fizemos pelo caminho? } \\
\text { Tente me dizer quem eles são. }\end{array}$ \\
\hline
\end{tabular}

\section{Referências}

AZENHA JUNIOR, J. Imagem e Texto: Criatividade na Aula de Tradução. III Encontro Paulista de Pesquisadores em Tradução. São Paulo: UNESP, 1995.

BARTHES, Roland. O Prazer do Texto. São Paulo: Editora Perspectiva, 2002.

ANDREAE, Giles. WOJTOWYCZ, David. Commotion in the Ocean. London: Scholastic Inc. 1998.

\section{Websites}

JENKINO, Lilian. Tradução de Livros para Crianças. Publicado em ETALK, SBS. Disponivel em: http://www.sbs.com.br/virtual/etalk/index.asp? cod=1027 